\title{
BMJ Open Attitudes on cost-effectiveness and equity: a cross-sectional study examining the viewpoints of medical professionals
}

\author{
David G Li, ${ }^{1}$ Gordon X Wong, ${ }^{1}$ David T Martin, ${ }^{2}$ David J Tybor, ${ }^{1}$ Jennifer Kim, ${ }^{3}$ \\ Jeffrey Lasker, ${ }^{4}$ Roger Mitty, ${ }^{5}$ Deeb Salem ${ }^{6}$
}

To cite: Li DG, Wong GX, Martin DT, et al. Attitudes on cost-effectiveness and equity: a cross-sectional study examining the viewpoints of medical professionals. BMJ Open 2017;7:e017251. doi:10.1136/ bmjopen-2017-017251

- Prepublication history for this paper is available online. To view these files please visit the journal online (http://dx.doi org/10.1136/bmjopen-2017017251).

Received 11 April 2017 Revised 30 May 2017 Accepted 21 June 2017

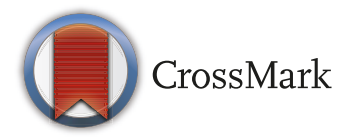

${ }^{1}$ Tufts University School of Medicine, Boston,

Massachusetts, USA

${ }^{2}$ Lahey Hospital and Medical Center, Burlington, Massachusetts, USA

${ }^{3}$ Stanford Medical Center, Palo Alto, California, USA

${ }^{4}$ New England Quality Care Alliance, Boston, Massachusetts, USA

${ }^{5}$ St. Elizabeth's Medical Center, Brighton, Massachusetts, USA

${ }^{6}$ Tufts Medical Center, Boston, Massachusetts, USA

Correspondence to

Dr Deeb Salem;

dsalem@tuftsmedicalcenter.org

\section{ABSTRACT}

Objective To determine the attitudes of physicians and trainees in regard to the roles of both cost-effectiveness and equity in clinical decision making.

Design In this cross-sectional study, electronic surveys containing a hypothetical decision-making scenario were sent to medical professionals to select between two colon cancer screening tests for a population.

Setting Three Greater Boston academic medical institutions: Tufts University School of Medicine, Tufts Medical Centre and Lahey Hospital and Medical Centre.

Participants 819 medical students, 497 residents-intraining and 671 practising physicians were contacted electronically using institutional and organisational directories.

Main outcome(s) and measure(s) Stratified opinions of medical providers and trainee subgroups regarding costeffectiveness and equity.

Results A total of 881 respondents comprising 512 medical students, 133 medical residents-in-training and 236 practising physicians completed the survey (total response rate $44.3 \%$ ). Thirty-six per cent of medical students, $44 \%$ of residents-in-training and $53 \%$ of practising physicians favoured the less effective and more equitable screening test. Residents-in-training (OR 1.49, Cl 1.01 to 2.21; $p=0.044$ ) and practising physicians (OR 2.12, Cl 1.54 to $2.92 ; \mathrm{p}<0.001$ ) were more likely to favour the equitable option compared with medical students. Moreover, female responders across all three cohorts favoured the more equitable screening test to a greater degree than did male responders $(\mathrm{OR} 1.70, \mathrm{Cl} 1.29$ to 2.24; $p<0.001$ ).

Conclusions Cost-effectiveness analysis does not accurately reflect the importance that medical professionals place on equity. Among medical professionals, practising physicians appear to be more egalitarian than residents-in-training, while medical students appear to be most utilitarian and cost-effective. Meanwhile, female respondents in all three cohorts favoured the more equitable option to a greater degree than their male counterparts. Healthcare policies that trade off equity in favour of cost-effectiveness may be unacceptable to many medical professionals, especially practising physicians and women.
Strengths and limitations of this study

To our knowledge, this study is the first to examine the attitudes on cost-effectiveness and equity among medical cohorts and by gender.

- A cross-sectional study design was utilised to evaluate the stratified opinions of 512 medical students, 133 residents-in-training and 236 practising physicians at three academic medical institutions.

- This study provides an important baseline for future longitudinal studies that examine the change in opinions on cost-effectiveness and equity among medical professionals-domestically and internationally.

- Given the cross-sectional nature of the study, our results provide information on the current attitudes among medical professionals, but not regarding how these attitudes may evolve over the course of time.

- Our response is $44.3 \%$ among all cohorts; nonetheless, respondent demographics appear to be congruent with national distributions.

- Respondents were pooled from academic medical institutions in the Greater Boston region, and thus, opinions may not be generalisable nationally.

\section{BACKGROUND}

Cost-effectiveness in healthcare compares the benefits of a treatment to its costs. When faced with budget constraints, physicians can use cost-effectiveness principles to optimise the yield of a strategy in terms of quality-adjusted life years to make important treatment decisions that provide the greatest benefit to patients. However, there are limitations to this method. ${ }^{12}$ Budget constraints can restrict access to potentially beneficial therapies, ${ }^{3}$ necessitating the need to balance cost-effectiveness with equity, defined in this context as uniform distribution of resources and access to care. ${ }^{4}$ 
In 1996, Ubel et al examined the opinions on cost-effectiveness versus medical equity across three groups: members of the general public (prospective jurors from Philadelphia), medical ethicists from the American Association of Bioethics and medical decision-making experts from the Society for Medical Decision Making. The study revealed that substantial proportions, $56 \%, 53 \%$ and $41 \%$, respectively, when asked to choose between two screening tests for a hypothetical population, prioritised the more equitable screening test over the more cost-effective screening test that saves more lives but that could be administered only to half of the population. This study suggests that healthcare equity is an influential factor in medical decision making and that cost-effectiveness should not be the sole factor considered in medical policy making. ${ }^{2}$ The healthcare landscape has undergone many changes for all stakeholders since the 1996 study's publication. ${ }^{56}$ With shifts from fee-for-service to bundled payments/capitation under The Affordable Care Act, healthcare decision making faces new challenges in the allocation of medical spending. This raises the question: how might Ubel's findings from 20 years ago generalise to the current populations of medical students, residents-intraining and practising physicians? ${ }^{78}$

Identifying the current opinions of medical professionals regarding the tensions between healthcare equity and cost-effectiveness may provide greater insight toward shaping treatment guidelines, screening recommendations and government healthcare policies. ${ }^{9} 10$ The emerging focus on cost-effectiveness may play an increasingly prominent role in a physician's decision-making process, and this must be balanced with attention to equity in achieving the highest priority: patient wellbeing. ${ }^{11}$ Meanwhile, progression through undergraduate and graduate medical training has been reported to be associated with a shift in attitudes, loss of idealism and less empathy towards patients. ${ }^{12-14}$

Current literature lacks discussion on the attitudes of the medical community regarding the balancing of cost-effectiveness and equity in the use of and access to treatments. This study aims to provide stratified analyses of medical providers' and provider trainee subgroups' opinions while also investigating disparities in opinions among gender and age groups. The goal of our research was to examine whether medical students, residents-intraining and practising physicians would provide different responses when presented with a hypothetical medical scenario that asked them to choose either an equitable option or a cost-effective option and whether age and gender modified those choices.

\section{METHODS}

\section{Subjects}

Individuals from Tufts-University-affiliated institutions (residents and physicians from Tufts Medical Centre, a moderate-sized tertiary care hospital; Lahey Hospital and Medical Centre, a moderate-sized community-based medical centre; medical students from Tufts University School of Medicine) were contacted by an electronic survey using the sample frame of institutional and organisational directories. Responses were collected by an online survey system (Qualtrics, Provo, Utah, USA). Medical students were recruited by announcing that, on completion of the survey, as compensation, $20 \$ 25$ Amazon gift card incentives would be randomly raffled and electronically distributed to medical students completing the survey. Like Ubel's study, we provided incentives only to the largest expected respondent population, which were medical students in our study. Therefore, residents-intraining and practising physicians were not offered any financial incentives. All cohorts received invitations to complete the electronic surveys on three occasions, separated by 2-week intervals. The study was approved by the Tufts Health Sciences Campus institutional review board.

\section{Survey}

All respondents were presented with the following scenario from the 1996 Ubel et al study:

'A group of doctors was formed to help the government decide which of two tests to offer low-risk people. Test 1 [the more equitable option] is inexpensive but does not always detect cancers in their early stages. Test 2 [the more cost-effective option] is more expensive but is better at detecting early cancers. The decision is complicated by budget limitations: the government has only a certain amount of money available to pay for the screening tests. After evaluating the costs and benefits of each test, the doctors have reached the following conclusions. The budget is just large enough to offer Test 1 [the equitable option] to all the low-risk people. With this approach, everyone can receive the test, and 1000 deaths from colon cancer will be prevented. The budget is just large enough to offer Test 2 [the cost-effective option] to half of the low-risk people. With this approach, half of the people can receive the test and half cannot, and 1100 deaths from colon cancer will be prevented.' ${ }^{2}$

All respondents were asked to choose which screening test they would offer and to provide their reasoning for the choice. Respondents also reported their gender, age and specialty of practice.

\section{Statistical analysis}

The dependent variable of interest was the proportion of subjects who chose test 1 (the equitable option) over test 2 (the cost-effective option). To see if the odds of choosing the equitable option over the cost-effective option were different for medical students, residents-in-training and practising physicians, we conducted a simple binary logistic regression and included a test for trend across the spectrum of medical education and practice (model A). In a separate model, we compared whether men and women had different odds of selecting the equitable option (model B). Using a multiple logistic regression, we examined the independent effect of gender and cohort on the probability of selecting the equitable option (model C) and tested for effect modification. In secondary analyses, 
Table 1 Demographic characteristics of survey respondents

\begin{tabular}{llll}
\hline & $\begin{array}{l}\text { Medical } \\
\text { students } \\
(\mathbf{n}=512)\end{array}$ & $\begin{array}{l}\text { Residents- } \\
\text { in-training } \\
(\mathbf{n}=133)\end{array}$ & $\begin{array}{l}\text { Practising } \\
\text { physicians } \\
(\mathbf{n}=\mathbf{2 3 6})\end{array}$ \\
\hline Mean age (SD) & $26(2.7)$ & $30(4.2)$ & $48(12.0)$ \\
Female & $54 \%$ & $49 \%$ & $46 \%$ \\
\hline
\end{tabular}

among medical students, we examined whether the year of medical school was a significant predictor of which hypothetical screening programme was chosen. Similarly, among practising physicians, we examined the role of age. Incomplete survey responses $(9.3 \%$ of all surveys started) lacking test preference and/or the majority of demographic information were not used for the study. We conducted all statistical tests with a two-sided alpha level of 0.05 using Stata v14 (College Station).

\section{RESULTS}

Surveys were sent to 819 medical students, 497 residentsin-training and 671 practising physicians, pooled from the aforementioned medical centres. A total of 881 respondents $(44.3 \%$ total response rate) completed the survey: 512 medical students (62.5\% response rate), 133 residents-in-training $(26.8 \%)$ and 236 practising physicians $(35.2 \%)$ (table 1$)$.

When presented with the option of either an equitable screening programme or a cost-effective screening programme, $36 \%$ of medical students, $44 \%$ of residentsin-training and $53 \%$ of physicians chose the equitable

\begin{tabular}{|c|c|c|c|}
\hline & & $\begin{array}{l}\text { Equitable } \\
\text { option } \\
\text { (saves } 1000 \\
\text { lives) (\%) } \\
\end{array}$ & $\begin{array}{l}\text { Cost-effective } \\
\text { option } \\
\text { (saves } 1100 \\
\text { lives) }(\%)\end{array}$ \\
\hline \multicolumn{4}{|l|}{ Males } \\
\hline & $\begin{array}{l}\text { Medical students } \\
(n=236)\end{array}$ & 29 & 71 \\
\hline & $\begin{array}{l}\text { Residents-in- } \\
\text { training }(n=68)\end{array}$ & 38 & 62 \\
\hline & $\begin{array}{l}\text { Practising } \\
\text { physicians } \\
(n=128)\end{array}$ & $47^{*}$ & 53 \\
\hline \multicolumn{4}{|l|}{ Females } \\
\hline & $\begin{array}{l}\text { Medical students } \\
(n=276)\end{array}$ & 41 & 59 \\
\hline & $\begin{array}{l}\text { Residents-in- } \\
\text { training }(n=65)\end{array}$ & 51 & 49 \\
\hline & $\begin{array}{l}\text { Practising } \\
\text { physicians } \\
(n=108)\end{array}$ & $59^{\star}$ & 41 \\
\hline
\end{tabular}

*Within each gender, increased experience leads to increased odds of choosing the equitable option $(p<0.001)$ by test for trend. option, with women more likely to choose the equitable option within each strata (table 2). Physicians were 2.01 times as likely as medical students to select the equitable option, and residents-in-training were 1.44 times as likely as medical students to select the equitable option (simple logistic regression, table 3 , model A, test for trend, $\left.\chi^{2}=21.5, \mathrm{p}<0.001\right)$. Women were 1.6 times as likely as men to select the equitable programme (simple logistic regression, $\mathrm{p}=0.001$, table 3 , model $\mathrm{B}$ ).

Gender was a significant predictor of screening option choice, and because it was unequally distributed among students, residents-in-training and physicians, we constructed a multiple logistic regression model to control for confounding and quantify the independent effects of these two variables. After controlling for gender, residents-in-training were 1.49 times as likely as medical students to choose the equitable option (OR 1.49 , CI 1.01 to $2.21 ; \mathrm{p}=0.044$ ), and physicians were 2.12 times as likely as medical students to select the equitable option (OR 2.12, CI 1.54 to 2.92; $\mathrm{p}<0.001$, table 3, model C). Independent of career status, women were 1.7 times as likely as men to choose the equitable screening programme (OR 1.70, CI 1.29 to 2.24; $\mathrm{p}<0.001$, table 3, model C).

In secondary analyses (not shown), there was no evidence of a statistically significant interaction between gender and cohort; the effect of gender was consistent across medical students, residents-in-training and physicians, as can be seen in table 1 . Among medical students, there was no evidence that the year in school affected which screening option was chosen, after controlling for gender $(p=0.205)$. Similarly, among physicians, after controlling for gender, there was no evidence that age affected which screening option was selected $(\mathrm{p}=0.192)$.

Respondents also provided reasons for why test 1 or test 2 was chosen. Respondents who selected in favour of the more cost-effective test (test 2) most commonly reasoned that it would prevent more total deaths and save a greater number of lives. Despite the more cost-effective test maximising health benefits across the entire health system, many respondents rejected this test on the premise that it was unfair, unethical and could not be distributed equally to all members of the hypothetical population. Similarly, some respondents were concerned how half of the population could be selected in a fair and unbiased manner.

\section{DISCUSSION}

\section{Principal findings and implications}

Our data suggest that attitudes about decision making related to balancing cost-effectiveness and equity differ across medical students, residents-in-training and practising physicians, as well as by gender.

While the respondents of the medical student cohort demonstrated a majority preference for utilitarian cost-effectiveness over equity, the respondents of the resident-in-training and practising physician cohorts preferred the more equitable cancer screening strategy 


\begin{tabular}{|c|c|c|c|}
\hline & Model A OR (95\% Cl) & Model B OR (95\% CI) & Model C OR $(95 \% \mathrm{Cl})$ \\
\hline \multicolumn{4}{|l|}{ Group } \\
\hline Medical students & (Reference) & & (Reference) \\
\hline Residents-in-training & 1.44 (0.98 to 2.13$)$ & & 1.49 (1.01 to 2.21$)$ \\
\hline Practising physicians & 2.01 (1.47 to 2.75$)$ & & $2.12(1.54 \text { to } 2.92)^{*}$ \\
\hline \multicolumn{4}{|l|}{ Gender } \\
\hline Males & & (Reference) & (Reference) \\
\hline Females & & 1.60 (1.22 to 2.10$)$ & 1.70 (1.29 to 2.24$)$ \\
\hline
\end{tabular}

${ }^{*}$ After controlling for gender, increased experience leads to increased odds of selecting the equitable option $(p<0.001)$ by test for trend.

(table 3). Based on the literature on medical training and empathy, our initial hypothesis postulated a shifting emphasis from equity to cost-effectiveness among the cohorts, in the progression from student to resident to practising physician. However, we found the opposite trend (table 3). In the scenario borrowed from Ubel's 1996 study, 100 more lives would be saved under the more cost-effective approach compared with the strategy that emphasised equity. ${ }^{2}$ Yet, more than half of practising physicians in our study chose in favour of equity in access to cancer screening, despite saving 100 fewer lives from colon cancer in the hypothetical scenario. This suggests that the responding physicians preferred avoidance of inequity in medical care, even at the cost of saving fewer lives. Nonetheless, because our data are cross-sectional rather than longitudinal, we can only infer that current students are more willing to trade off equity for cost-effectiveness compared with their current resident and physician mentors. ${ }^{1215}$

Students' responses favoured choosing a test that would save more lives and provide the most benefit to patients. But why are medical students so 'cost-effective' in this regard, a finding less seen among the residents-in-training and physicians? One explanation is that the idealism of medical students has not been challenged as much by the pragmatic demands of clinical care as experienced by residents-in-training and physicians, who favour equality in access to care, even if it means saving fewer lives. ${ }^{16}{ }^{17}$ It has been suggested that medical students' approaches to ethical dilemmas are complicated by their own pursuit of knowledge and ethical views strictly tailored to their roles, and thus, students can be expected to respond to such scenarios differently than residents-in-training or physicians. ${ }^{18}$ Another explanation is that medical students, less experienced in clinical decision making, focus more on outcomes over the means, thus favouring the utilitarian cost-effective option. Meanwhile, residents-in-training and physicians place greater weight on Kantian principles of motives and morals, generally favouring the more egalitarian choice. ${ }^{19}$ Therefore, are medical students less ethical than residents/physicians in the Kantian sense, and will the roles of Kantian and utilitarian principles within medical education change as medical care evolves under healthcare policy changes and cost pressures?20 21
Finally, females in our study were 1.7 times as likely as males to choose the more equitable option over the cost-effective option. According to validated indices, women are more empathetic than men, ${ }^{1622} 23$ and a recently published study found this among female medical students. ${ }^{24}$ Our results further imply that female students, residents and physicians as a whole are more egalitarian in their decision making, while their male counterparts are more utilitarian.

\section{Comparison with other studies}

Direct comparisons of cost-effectiveness attitudes between the clinicians in our study and the jurors, ethicists and medical decision makers in Ubel's study are difficult given the differing natures of the subpopulations. Ubel's study surveyed jurors (no response rate reported), medical ethicists (74\% response rate), and decision-making experts (73\% response rate). However, Ubel's study did not appear to account for the effect modification of gender on cost-effectiveness attitudes. ${ }^{2}$ In Ubel's study, $64 \%$ of jurors and $22 \%$ of decision-making experts were female, with $56 \%$ and $46 \%$ of these respective cohorts choosing the more equitable option. Had Ubel controlled for gender, would a female preference towards equity have been realised? Moreover, a 1993 study suggested that gender differences may influence physician decision making for gender-specific patient care, specifically in the higher utilisation rates of breast and cervical cancer screening among female physicians compared with male physicians. ${ }^{25}{ }^{26}$ Could differing attitudes toward cost-effectiveness between male and female physicians account for this observation?

A study by Perneger et al also used Ubel's scenario to evaluate Swiss physicians' attitudes on cost-effectiveness. ${ }^{27}$ Their study, which had a $59 \%$ response rate, found that $26 \%$ of physicians favoured cost-effectiveness, with the large majority favouring equity, and that there were no differences in opinions between male and female respondents. Our results differed with $47 \%$ of physicians favouring cost-effectiveness and with female physicians favouring equity more so than did their male counterparts. Cultural context and other socioeconomic factors may have influenced this difference in attitudes. European nations, in general, enjoy more equitable wealth 
distribution than the United States, and this may translate into attitudes favouring equity for other socioeconomic concerns, such as healthcare access. ${ }^{28}$ Moreover, the study by Perneger $e t$ al surveyed residents and practising physicians but only reported aggregate responses. ${ }^{27}$ It is therefore unclear whether the attitudes of residents differ from those of physicians and how they might compare with the results of our study.

\section{Strengths and limitations}

To our knowledge, our study is the first to examine the attitudes on cost-effectiveness among medical cohorts and by gender. In contrast to Ubel $e t a l$, this study collected and analysed a large sample size of responses from physicians and trainees to describe the medical community's varying opinions on cost-effectiveness and equity. ${ }^{2}$ Furthermore, the survey respondents were from the Greater Boston area and were affiliated with major academic medical centres. Thus, survey respondents demonstrated sufficient demographic heterogeneity, in terms of geographic and educational backgrounds, to appropriately reflect the general opinions of medical students, residents and physicians. Finally, our data can provide a meaningful baseline for future longitudinal studies to assess the change in opinions on cost-effectiveness and equity among medical professionals.

However, our study faced several limitations. Designed to be cross-sectional in nature, the study could not account for the influence of shifting social norms over time or for how maturity and life experiences may have affected responses. Second, our response rate was $44.3 \%$, and it is possible that those who responded are not a truly random sample of our populations of interest. In terms of demographics, the mean age of medical students nationally is 26 , and $48 \%$ are female; the mean age of students in our study is 24 , and $54 \%$ are female, a finding with mild variability from that of the national distribution. ${ }^{29}$ Nationally, $46 \%$ of residents-in-training are female with little data on the average age; in our study, $49 \%$ of residents-in-training are female and this appears similar to that of the national distribution. ${ }^{30}$ Moreover, it is also possible that those who favour the more equitable screening option also are more likely to respond to surveys, resulting in response bias and an underestimation of the true proportion of people preferring the cost-effective option. Likewise, perhaps the non-responders hold little or no opinion regarding cost-effectiveness versus equity, as it is not a primary topic discussed in medical education, and their contributions would not benefit the central discussion of our study. In either case, it is plausible that our data would be affected in a systematic manner across all three cohorts, not disrupting the observed trend and not obscuring the aggregate opinions. Finally, demographic information on ethnicity was not recorded. Although different ethnic groups may have varying emphases on specific values, we believe that the fundamental principles of medical equity and cost-effectiveness are generally understood by medical personnel of varying origins and would not be likely to affect their recommendations.

\section{Unanswered questions and future research}

Our study highlighted important differences in opinions between medical students, residents-in-training and practising physicians in balancing cost-effectiveness and equity in medical care. Among medical professionals, the results illustrated differences in this balancing between men and women. Both cost-effectiveness and equity are important aspects of healthcare policy, yet it may be that there is insufficient examination of their balance as operationalised in patient care. Neither principle can be applied exclusively. In light of our findings, were cost-effectiveness to play a greater role in determining medical priorities in the future, do these results imply that male and female healthcare workers will differ substantially in their decision making? How might this affect patients' gender preference for their healthcare providers? Further studies would be merited that examine whether women as a whole are inherently more equity driven and empathetic, whether patients prefer more equitable providers, how the attitudes of physicians and trainees differ across other health systems and whether the opinions of our studied populations differ nationally and internationally.

As healthcare costs and regulations shape the future of medicine, physicians may find an increased need to apply cost-effectiveness principles in the management of diverse patient populations. However, basing access to care only on cost-effectiveness analyses is likely to raise issues about equity of care distribution within the medical community. Thus, physicians and trainees may benefit from the incorporation of cost-effectiveness and equity principles within the spectrum of medical education. Our data suggest that this balancing will require consideration and discussion of the tradeoffs between equity and fairness in making such decisions.

Contributors DGL initiated the collaborative project, designed data collection tools, monitored data collection for the whole trial, cleaned and analysed the data and drafted and revised the paper. He is guarantor. GXW initiated the collaborative project, designed data collection tools, monitored data collection for the whole trial, cleaned and analysed the data and drafted and revised the paper. He is guarantor. DTM coordinated the collaborative project, monitored data collection and revised the paper. DJT wrote the statistical analysis plan, cleaned and analysed the data and revised the paper. JK monitored data collection for the trial and revised paper. $\mathrm{JL}$ coordinated the collaborative project, monitored data collection and revised the paper. RM coordinated the collaborative project, monitored data collection and revised the paper. DS initiated the collaborate project, interpreted and analysed data and revised the paper. Allison Ankeny of Tufts Medical Center and Derek Tu of Tufts University School of Medicine assisted with research in the early phases of the project. Janis Breeze of Tufts Clinical and Translational Science Institute assisted with data analysis. Harry Selker of Tufts Medical Center provided insightful comments that improved the manuscript.

Funding The project described was supported by the National Center for Advancing Translational Sciences, National Institutes of Health, Award Number TL1TR001062. The content is solely the responsibility of the authors and does not necessarily represent the official views of the $\mathrm{NIH}$.

Competing interests All authors have completed the International Committee of Medical Journal Editors uniform disclosure form at www.icmje.org/coi_disclosure. pdf and declare no support from any organization for the submitted work, no financial relationships with any organizations that might have an interest in the 
submitted work in the previous 3 years and no other relationships or activities that could appear to have influenced the submitted work.

Patient consent Not applicable. There are no patients in our study and no recognisable or identifying information is included.

Ethics approval Tufts Health Sciences Campus Institutional Review Board (IRB \#11941).

Provenance and peer review Not commissioned; externally peer reviewed.

Data sharing statement № additional data are available.

Open Access This is an Open Access article distributed in accordance with the Creative Commons Attribution Non Commercial (CC BY-NC 4.0) license, which permits others to distribute, remix, adapt, build upon this work non-commercially, and license their derivative works on different terms, provided the original work is properly cited and the use is non-commercial. See: http://creativecommons.org/ licenses/by-nc/4.0/

(c) Article author(s) (or their employer(s) unless otherwise stated in the text of the article) 2017. All rights reserved. No commercial use is permitted unless otherwise expressly granted.

\section{REFERENCES}

1. Cawley J. The cost-effectiveness of programs to prevent or reduce obesity: the state of the literature and a future research agenda. Arch Pediatr Adolesc Med 2007;161:611-4.

2. Ubel PA, DeKay ML, Baron J, et al. Cost-effectiveness analysis in a setting of budget constraints - is it equitable? N Engl J Med 1996;334:1174-7.

3. Peppercorn J, Zafar SY, Houck K, et al. Does comparative effectiveness research promote rationing of cancer care? Lancet Oncol 2014;15:e132-e138.

4. Ubel PA, Goold SD. 'Rationing' health care. Not all definitions are created equal. Arch Intern Med 1998;158:209-14.

5. Read the law: the Affordable Care Act, Section by Section. U.S. Department of Health \& Human Services Washington, D.C, 2015. http://www.hhs.gov/healthcare/about-the-law/read-the-law/index. html. (accessed 19 Jun 2016).

6. Kocher R, Emanuel EJ, DeParle NA. The Affordable Care Act and the future of clinical medicine: the opportunities and challenges. Ann Intern Med 2010;153:536-9.

7. Ware JE, Bayliss MS, Rogers WH, et al. Differences in 4-year health outcomes for elderly and poor, chronically ill patients treated in $\mathrm{HMO}$ and fee-for-service systems. Results from the Medical Outcomes Study. JAMA 1996;276:1039-47.

8. Potosky AL, Merrill RM, Riley GF, et al. Prostate cancer treatment and ten-year survival among group/staff $\mathrm{HMO}$ and fee-for-service Medicare patients. Health Serv Res 1999;34:525-46.

9. WHO Guide to Cost-Effective Analysis. Geneva: World Health Organization, 2003. http://www.who.int/choice/publications/p_2003_ generalised_cea.pdf. (accessed 19 June 2016).

10. Cost RMD. Effectiveness, and Value. How to Judge? JAMA 2016;316:1447-8.
11. La Puma J, Lawlor EF. Quality-adjusted life-years. Ethical implications for physicians and policymakers. JAMA 1990;263:2917-21.

12. Woloschuk W, Harasym PH, Temple W. Attitude change during medical school: a cohort study. Med Educ 2004;38:522-34.

13. Branch WT. Supporting the moral development of medical students. $J$ Gen Intern Med 2000;15:503-8.

14. Branch WT, Pels RJ, Hafler JP. Medical students' empathic understanding of their patients. Acad Med 1998;73:360-2.

15. Eikeland HL, Ørnes K, Finset A, et al. The physician's role and empathy - a qualitative study of third year medical students. BMC Med Educ 2014;14:165.

16. Mestre MV, Samper P, Frías MD, et al. Are women more empathetic than men? A longitudinal study in adolescence. Span J Psychol 2009;12:76-83.

17. Hojat M, Mangione S, Nasca TJ, et al. An empirical study of decline in empathy in medical school. Med Educ 2004;38:934-41.

18. Playford RC, Roberts T, Playford ED. Deontological and utilitarian ethics: a brief introduction in the context of disorders of consciousness. Disabil Rehabil 2015;37:2006-11.

19. Johnson R, Cureton A. In: Edward N Zalta. ed. "Kant's Moral Philosophy". The Stanford Encyclopedia of Philosophy (Spring 2017 Edition). https://plato.stanford.edu/archives/spr2017/entries/kantmoral. (accessed 9 Jan 2017).

20. Christakis DA, Feudtner C. Ethics in a short white coat: the ethical dilemmas that medical students confront. Acad Med 1993;68:249-54.

21. Heubel F, Biller-Andorno N. The contribution of Kantian moral theory to contemporary medical ethics: a critical analysis. Med Health Care Philos 2005;8:5-18.

22. Williams CA. Empathy and burnout in male and female helping professionals. Res Nurs Health 1989;12:169-78.

23. Toussaint L, Webb JR. Gender differences in the relationship between empathy and forgiveness. J Soc Psychol 2005;145:673-85.

24. Santos MA, Grosseman S, Morelli TC, et al. Empathy differences by gender and specialty preference in medical students: a study in Brazil. Int J Med Educ 2016;7:153-7.

25. Lurie N, Margolis KL, McGovern PG, et al. Why do patients of female physicians have higher rates of breast and cervical cancer screening? J Gen Intern Med 1997;12:34-43.

26. Lurie N, Slater J, McGovern P, et al. Preventive care for women. Does the sex of the physician matter? N Engl J Med 1993;329:478-82.

27. Perneger TV, Martin DP, Bovier PA. Physicians' attitudes toward health care rationing. Med Decis Making 2002;22:65-70.

28. Income Inequality Remains High in the Face of Weak Recovery, Income Inequality Update. The Organisation for Economic Cooperation and Development. 2016 https://www.oecd.org/social/ OECD2016-Income-Inequality-Update.pdf (accessed 19 Jan 2017).

29. Age of Applicants to U.S. Medical Schools at Anticipated Matriculation by Sex and Race/Ethnicity, 2013- 2014 through 2016-2017. Association of American Medical Colleges. 2016 https:// www.aamc.org/download/321468/data/factstablea6.pdf (accessed 26 May 2017).

30. ACGME residents and fellows by sex and Specialty, 2015. Association of American Medical Colleges. 2016 https://www.aamc. org/data/workforce/reports/458766/2-2-chart.html (accessed 26 May 2017). 